\title{
Editorial
}

\section{Invasive coronary revascularisation is better than conservative treatment in patients with acute coronary syndromes}

New advances in interventional cardiology and antithrombotic pharmacological treatment have modified the risk:benefit ratio of percutaneous interventions in acute coronary syndromes without ST segment elevation.

In general terms, invasive strategies have two main limitations. The first stems from the fact that the severity of a coronary stenosis is not an index of the likelihood of the development of clinical instability or future cardiovascular events. ${ }^{1}$ It is now well known that the main pathophysiological mechanism of acute coronary syndromes is destabilisation of the atherosclerotic plaque, which leads to fissuring and the consequent exposure of the subendothelium matrix. The critical factors determining the clinical manifestations and prognosis of these syndromes are the duration and degree of the reduction in coronary flow caused by thrombosis (and its variable associations with superimposed vasoconstriction), the coexistence of collateral flows, and the microvascular embolisation of platelet aggregates and atherothrombotic material. Given the lack of suitable instruments for evaluating the degree of plaque vulnerability and predicting its prothrombotic response, angiographic data alone are insufficient.

The second and more practical limitation concerns the complications of percutaneous revascularisation: in addition to severe complications such as dissection, vascular damage and consequent platelet activation, percutaneous interventions contribute towards the onset of adverse events caused by the occlusion of collateral vessels and the embolisation of atherothrombotic material with varying degrees of microvascular deterioration. Recent studies have found a correlation between the incidence of myocardial necrosis (as indicated by post-intervention enzyme release) and that of long term mortality. ${ }^{2-4}$

\section{Results of clinical trials}

It is therefore not surprising that the clinical data published before the introduction of the advances in these fields indicate the potentially negative effects of invasive treatment. The TIMI (thrombolyis in myocardial infarction) IIIB trial involved 1473 patients with unstable angina or non-Q wave acute myocardial infarction, but did not document any clinically meaningful difference in the incidence of the primary end point of death, myocardial infarction, and recurrent inducible ischaemia between the invasively and conservatively treated groups $(16.2 \% v 18.1 \%)$; however, the incidence of rehospitalisation at six weeks was $50 \%$ less in the patients who received early invasive treatment. ${ }^{5}$

The OASIS (organization to assess strategies for ischemic syndromes) registry of 8000 patients with unstable angina or non- $Q$ wave acute myocardial infarction showed that the patients receiving invasive treatment had a lower incidence of refractory angina than those who were conservatively treated; however, although the mortality and reinfarction rates in the countries in which early diagnostic catheterisation and revascularisation were performed more often were similar to those observed in the countries in which it was less frequent, the stroke rate was higher. ${ }^{6}$
The VANQWISH (Veteran Affairs non-Q wave infarction strategies in hospital) trial randomised 920 patients to invasive or conservative treatment within 1-3 days of a non-Q wave myocardial infarction. Cumulative all cause mortality was not significantly different between the two groups during long term follow up (death and non-fatal acute myocardial infarction was $29.9 \%$ in the invasive arm and $26.9 \%$ in the conservative arm, $\mathrm{p}=0.35$ ); however, the incidence of cardiac death and non-fatal myocardial infarction in the invasively treated group was 2-3 times higher at the time of hospital discharge and after 30 days, and remained higher throughout the first year. ${ }^{7}$

The results of the recent FRISC II (fast revascularisation during instability in coronary artery disease) and TACTICS (treat angina with Aggrastat and determine cost of therapy or conservative strategy)-TIMI 18 trials of a modern antithrombotic treatment regimen added to extensive stenting procedures in the management of acute coronary syndromes without persistent ST segment elevation have now tilted the scales in favour of invasive strategies. In the FRISC II trial, ${ }^{8}$ after a period of stabilisation, the incidence of the composite end point of death or myocardial infarction at one year was lower in the 1222 patients assigned to invasive treatment than in the 1235 conservatively treated patients $(10.4 \%$ v $14.1 \%)$, with a $3.7 \%$ absolute and $26 \%$ relative risk reduction, although there was a higher rate of periprocedural myocardial infarction in the invasive group possibly because glycoprotein inhibitors were not used. Stenting alone has reduced the need for repeat percutaneous revascularisation and the risk of early acute mechanical occlusion by allowing better control over dissections and an increased lumen size, but has not reduced the incidence of acute periprocedural complications..$^{9-11}$

\section{Glycoprotein IIb/IIIa inhibitors}

A number of randomised trials ${ }^{12-17}$ have shown that the administration of glycoprotein IIb/IIIa inhibitors can protect against life threatening thrombosis, and that their use during stenting further reduces the adverse effects of revascularisation by synergistically combining the stent related lower incidence of reinterventions with an inhibitor related lower incidence of ischaemic events.

This synergistic benefit can be clearly seen in the results of the TACTICS-TIMI 18 trial, which confirmed the superiority of invasive over conservative strategies in reducing the incidence of the primary end point of death, myocardial infarction, and rehospitalisation at six months $(15.9 \% v 19.4 \%) .{ }^{17}$ The trial also showed that the use of tirofiban before revascularisation reduced the risk of acute periprocedural complications and improved the safety of the invasive treatment.

Waiting for the pharmacological stabilisation of acute coronary syndrome is no longer advisable. The exciting 
prospect for the future is that we will be able to recognise plaques undergoing complications and thus have the possibility of adopting a more directed intervention.

GIANLUCA GONZI

PIERA ANGELICA MERLINI*

Ospedale Maggiore di Parma, DIEGO ARDISSINO

University of Parma, Parma

*Division of Cardiology,

Ospedale Niguarda Ca' Granda,

Milan, Italy

Correspondence to: Dr Diego Ardissino, Division of Cardiology, Ospedale Maggiore di Parma, Università degli Studi di Parma, Via Gramsci 14, 43100 Parma, Italy; cardiologia.parma@ao.pr.it

1 Fuster V, Badimon L, Cohen M, et al. Insights into the pathogenesis of acute ischemic syndromes. Circulation 1988;77:1213-20.

2 Topol EJ, Ferguson JJ, Weisman HF, et al. Long-term protection from myocardial ischemic events in a randomized trial of brief integrin beta3 blockade with percutaneous coronary intervention. EPIC investigator group. Evaluation of platelet IIb/IIIa inhibition for the prevention of ischemic complications. $\mathscr{f} A M A$ 1997;278:479-84.

3 Abdelmeguid AE, Topol EJ, Whitlow PL, et al. Significance of mild transient release of creatine kinase-MB fraction after percutaneous coronary interventions. Circulation 1996;94:1528-36.

4 Kong TQ, Davidson CJ, Meyers SN, et al. Prognostic implications of creatine kinase elevation following elective coronary artery interventions. $\mathcal{F} A M A$ 1997;277:461-6.

5 TIMI IIIB Investigators. Effects of tissue plasminogen activator and a comparison of early invasive and conservative strategies in unstable angina and non-Q-wave myocardial infarction. Results of the TIMI IIIB trial (throm-

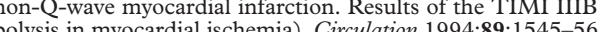

6 Yusuf S, Flather M, Pogue J, et al. Variations between countries in invasive cardiac procedures and outcomes in patients with suspected unstable cardiac procedures and outcomes in patients with suspected unstable (organisation to assess infarction without initial ST elevation. OASIS (organisation to assess strategies
gators. Lancet 1998;352:507-14.
7 Boden WE, O'Rourke RA, Crawford $\mathrm{MH}$, et al for the Veteran Affairs NonQ-wave Infarction Strategies in Hospital (VANQWISH) Trial InvestigaQ-wave Infarction Strategies in Hospital (VANQWISH) Trial Investigators. Outcomes in patients with acute non-Q-wave myocardial infarction randomly assigned to an invasive as compared with a conservative manage-

8 Wallentin L, Lagerqvist B, Husted S, et al. Outcome at 1 year after an invasive compared with a non-invasive strategy in unstable coronary-artery disease: the FRISC II invasive randomised trial. FRISC II investigators. Fast revascularisation during instability in coronary artery disease. Lancet 2000;356:9-16.

9 Fischman DL, Leon MB, Baim DS, et al. A randomized comparison of coronary-stent placement and balloon angioplasty in the treatment of coronary artery disease. Stent restenosis study investigators. $N$ Engl f Med 1994;331:496-501.

10 Serruys PW, de Jaegere P, Kiemeneij F, et al. A comparison of balloon-expandable-stent implantation with balloon angioplasty in patients with coronary artery disease. Benestent study group. $N$ Engl $\mathcal{F}$ Med 1994;331:489-95.

11 Serruys PW, van Hout B, Bonnier $\mathrm{H}$, et al. A randomised comparison of implantation of heparin-coated stents with balloon angioplasty in selected implantation of heparin-coated stents with balloon angioplasty in

12 The EPIC Investigation. Use of a monoclonal antibody directed against the platelet glycoprotein IIb/IIIa receptor in high-risk coronary angioplasty. $N$ Engl f Med 1994:330:956-61.

13 The EPILOG Investigators. Platelet glycoprotein IIb/IIIa receptor blockade and low-dose heparin during percutaneous coronary revascularization. $N$ Engl f Med 1997;336:1689-96.

14 The EPISTENT Investigators. Randomised placebo-controlled and balloon-angioplasty-controlled trial to assess safety of coronary stenting with use of platelet glycoprotein-IIb/IIIa blockade. Evaluation of platelet IIb/IIIa inhibitor for stenting. Lancet 1998;352:87-92.

15 IMPACT-II Investigators. Randomised placebo-controlled trial of effect of eptifibatide on complications of percutaneous coronary intervention: IMPACT-II. Integrilin to minimise platelet aggregation and coronary thrombosis-II. Lancet 1997;349:1422-8.

16 The RESTORE Investigators. Effects of platelet glycoprotein IIb/IIJ blockade with tirofiban on adverse cardiac events in patients with unstable angina or acute myocardial infarction undergoing coronary angioplasty. Randomized efficacy study of tirofiban for outcomes and restenosis. CircuRation 1997:96:1445-53.

17 Cannon CP, Weintraub WS, Demopoulos LA, et al. Comparison of early invasive and conservative strategies in patients with unstable coronary syndromes treated with the glycoprotein IIb/IIIa inhibitor tirofiban. $N$ Engl f Med 2001;344:1879-87.

\section{STAMPS IN CARDIOLOGY}

\section{Interventional cardiology}

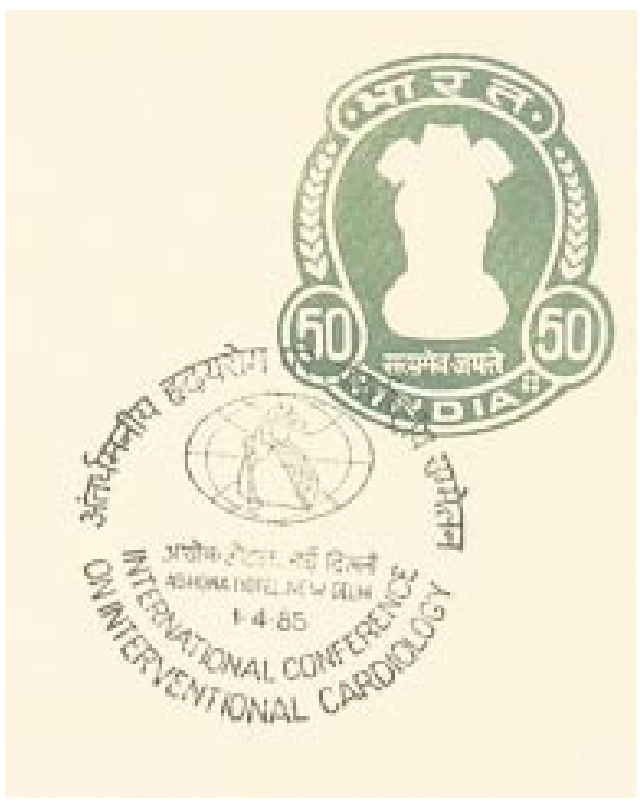

Although there are no stamps concerning this field of cardiology, the illustrated slogan cancellation was used to mark the International Conference on Interventional Cardiology held at the Ashoka Hotel, New Delhi on 1 April 1985

$M$ K DAVIES A HOLLMAN 